\title{
Protistan parasite QPX of hard-shell clam Mercenaria mercenaria is a member of Labyrinthulomycota
}

\author{
Mark A. Ragan ${ }^{1,2, *}$, Greg S. MacCallum ${ }^{3}$, Colleen A. Murphy ${ }^{1}$, Jamie J. Cannone ${ }^{4}$, \\ Robin R. Gutell ${ }^{4}$, Sharon E. McGladdery ${ }^{3}$ \\ ${ }^{1}$ Institute for Marine Biosciences, National Research Council of Canada, 1411 Oxford St, Halifax, Nova Scotia B3H 3Z1, Canada \\ ${ }^{2}$ Canadian Institute for Advanced Research, Program in Evolutionary Biology, 180 Dundas Street West, Suite 1400, Toronto, \\ Ontario M5G 1Z8, Canada \\ ${ }^{3}$ Fisheries and Oceans Canada, PO Box 5030, Moncton, New Brunswick E1C 9B6, Canada \\ ${ }^{4}$ Institute for Cellular and Molecular Biology, University of Texas, Austin, Texas 78712-1095, USA
}

\begin{abstract}
Biomass of the protistan parasite QPX (quahaug parasite X) of hard-shell clam Mercenaria mercenaria was enriched from in vitro culture. The nuclear gene encoding the 18S RNA of the small-subunit ribosomal (ssu-rDNA) was recovered using the polymerase chain reaction (PCR) and sequenced. Phylogenetic analysis clearly showed that QPX is a member of phylum Labyrinthulomycota, within which it appears as a specific relative of Thraustochytrium pachydermum. These results confirm the provisional assignment of QPX to the Labyrinthulomycota made previously on the basis of morphological and ultrastructural characters found in some, but not all, geographic isolates.
\end{abstract}

KEY WORDS: QPX, quahaug parasite X · Mercenaria mercenaria $\cdot$ Hard-shell clam · Small-subunit ribosomal DNA $\cdot$ Labyrinthulomycota $\cdot$ Thraustochytrium pachydermum

Resale or republication not permitted without written consent of the publisher

\section{INTRODUCTION}

The protist QPX (quahaug parasite $X_{\text {; }}$ McGladdery et al. 1993) was described as the causative agent of a 1962 mass mortality of quahaugs (hard-shell clam Mercenaria mercenaria) in New Brunswick, Canada. The same or similar organisms have subsequently been implicated in mortalities among wild stocks, and in at least 1 shellfish hatchery, from Massachusetts, USA, to Prince Edward Island, Canada. Initially the causative agent was referred to as an Olpidium-like chytrid (Drinnan \& Henderson 1963). Although QPX isolated from $M$. mercenaria in Atlantic Canada has not been reported to exhibit the ectoplasmic net char-

\footnotetext{
*Present address: Institute for Molecular Bioscience, The University of Queensland, Brisbane, Queensland 4072, Australia. E-mail:m.ragan@imb.uq.edu.au
}

acteristic of members of phylum Labyrinthulomycota (labyrinthulids and thraustochytrids), observations that it exhibits a uninucleate biflagellate zoospore stage, a loose multilaminar cell wall, and particularly an intracellular sagenogen-like structure led Whyte et al. (1994) to propose that QPX is related not to chytrids, but to thraustochytrids or labyrinthulids. A similar parasite recovered from $M$. mercenaria in Massachusetts produced at least small filaments, which Kleinschuster et al. (1998) have identified as ectoplasmic net, although sagenogens have not yet been detected in Massachusetts QPX (Kleinschuster et al. 1998, Smolowitz et al. 1998).

Members of phylum Labyrinthulomycota are widespread in marine, estuarine and other saline aquatic environments. Labyrinthulids occur commonly on marine vascular plants, macroalgae and organic detritus in the near-shore marine environment; thraustochy- 
trids are found in similar environments, although more typically in association with decomposing plant material or organic detritus than on living plants or algae. A few are of economic importance: Labyrinthula macrocystis has been implicated in the decline of shellfish fisheries along the Atlantic coasts of North America and Europe during the 1930s, due to its (perhaps secondary) role in the 'wasting disease' of the eelgrass Zostera marina (Pokorny 1967), while Labyrinthuloides haliotidis is a pathogen of the abalones Haliotis kamtschatkana and $H$. rufescens, causing up to $100 \%$ mortality in juveniles (Bower 1987a,b, Bower et al.1994).

Using the culture method developed by Kleinschuster et al. (1998), we enriched biomass of QPX from infected Mercenaria mercenaria isolated from New Brunswick, and have used the polymerase chain reaction (PCR) to amplify the nuclear gene encoding the small-subunit ribosomal RNA (ssu-rDNA) from this enriched fraction.

\section{METHODS AND MATERIALS}

Biological samples. Infected Mercenaria mercenaria ranging in size from 40 to $87 \mathrm{~mm}$ were collected from Sam Orr Pond, St Andrews, New Brunswick, on 16 July 1998. Within $24 \mathrm{~h}$ of removal from the water, a dorso-ventral cross-section of tissues was removed from each clam and preserved in 1G4F (Howard \& Smith 1983) for histological examination. At the same time, approximately $1 \mathrm{~mm}^{3}$ samples of gill, mantle, digestive gland, gonad and foot were collected for culture in Minimal Essential Medium (MEM; Sigma M0644).

Separation of parasites from tissues. The methods we employed are slight modifications of those used by Bower (1987c) for culture of Labyrinthuloides haliotidis in juvenile abalone (Haliotis rufescens and H. kamtschatkana). The combined tissues were macerated in a $10 \mathrm{ml}$ Potter Elvehjem tissue grinder with $1 \mathrm{ml}$ sterile artificial seawater (SAS). The homogenate was transferred to a $15 \mathrm{ml}$ capped centrifuge tube (Fisher) with an additional $2 \mathrm{ml}$ SAS containing antibiotics (10 $000 \mathrm{U}$ penicillin, $10000 \mu \mathrm{g}$ streptomycin and $25 \mu \mathrm{g}$ amphotericin $\mathrm{B} \mathrm{ml}^{-1} \mathrm{SAS}$ ). The homogenate was centrifuged at $1750 \times g$ in a benchtop centrifuge at $4^{\circ} \mathrm{C}$ for $7 \mathrm{~min}$, and the resultant pellet resuspended in $3 \mathrm{ml}$ SAS. The solution was then re-centrifuged and the pellet re-suspended in $7 \mathrm{ml}$ MEM prepared as described by Kleinschuster et al. (1998).

Culture and sub-culture. The culture solution was transferred to a $25 \mathrm{ml}$ canted-neck tissue flask (Corning) and incubated at $20^{\circ} \mathrm{C}$ in darkness. The MEM was changed every $3 \mathrm{~d}$, and the cultures were examined for QPX proliferation using an inverted microscope $(20 \times$ and $40 \times$ magnifications). Sub-samples from viscous mats of spherical organisms which developed, adhering to the bottom of the culture flasks, were wetmounted on glass slides and compared with positive histology preparations using a compound light microscope $(25 \times$ and $400 \times$ magnifications). Morphological characteristics such as size, thickness of spore walls, and evidence of endogenous sporogony were used to confirm the cultures as QPX-positive.

Sub-culturing was achieved by shaking the flasks gently and apportioning the contents between 2 flasks with fresh MEM on a fortnightly, and later weekly, basis. This permitted continuous cultures to be maintained over a period of 5 mo (August through December 1998). By November, however, the cultures began to show an increased level of QPX degeneration and fungal contamination, and were eventually discarded.

QPX organisms from 2 positive cultures, derived from quahaugs with positive histology, were collected, centrifuged twice in SAS to remove excess MEM, and re-suspended in $2 \mathrm{ml}$ of $0.2 \mu \mathrm{m}$ filtered SAS. The resulting isolates were frozen and stored at $-70^{\circ} \mathrm{C}$ until delivery to the NRC Institute for Marine Biosciences (IMB) on 29 September 1998 for DNA analysis. Fresh (unfrozen) biomass from active cultures was also transferred to IMB on this date.

Controls and contaminants. A second set of samples prepared using the same procedures described above, and stored at $-70^{\circ} \mathrm{C}$, was transferred to IMB on 21 December 1998. These cultures had been derived from seed clams collected for the time zero sample of a separate investigation of QPX transmission. Two of these culture samples, derived from clams 14 to $16 \mathrm{~mm}$ in length, lacked the viscosity normally associated with enrichments of QPX, but instead showed evidence of contamination by a filamentous fungus (see 'Results'); histology sections collected from the same clams showed no evidence of QPX infection. Two other culture samples, derived from clams 13 to $16 \mathrm{~mm}$ in length and which showed no histological or culture evidence of QPX or the fungal contaminant, were submitted as controls. Additional fresh (unfrozen) biomass from QPX cultures was transferred to IMB on 21 December.

DNA methods. The notably viscous samples of QPXenriched biomass from the positive cultures were washed repeatedly with phosphate-buffered saline $\left(\mathrm{PBS}_{\text {; }}\right.$ Sambrook et al. 1989) and pelleted at $1750 \times g$ using a benchtop centrifuge. DNA was extracted using the Easy-DNA kit (Invitrogen) with a protease step at $60^{\circ} \mathrm{C}$ (Invitrogen's protocol 8) to aid rupture of cells, precipitated and washed with ethanol, dried, resuspended in TE buffer (Sambrook et al. 1989), and treated with RNase A $\left(37^{\circ} \mathrm{C}, 30 \mathrm{~min}\right)$. The ssu-rDNAs were PCR-amplified using the GeneAmp XL PCR kit (Perkin Elmer BioSystems) with universal eukaryotic 
oligonucleotide primers $\left(\mathrm{GO}_{1}\right.$ and $\mathrm{GO}_{7}$; Saunders \& Kraft 1994). Thirty amplification cycles were carried out $\left(94^{\circ} \mathrm{C}\right.$ melting for $15 \mathrm{~s}, 65^{\circ} \mathrm{C}$ extension for $8 \mathrm{~min}$; PEC 9600 cycler), with the extension step successively extended by $15 \mathrm{~s}$ in each of the final 12 cycles. The amplicon (ca 1900 bp) was purified on an agarose gel (GeneClean, Bio101) and, except where stated otherwise, was PCR-sequenced directly (Perkin Elmer BioSystems' BigDye terminator chemistry) on an ABI 377 automated sequencer.

Parallel extractions and sequencing reactions were performed on the uninfected Mercenaria mercenaria tissue and on the culture material that showed evidence of fungal contamination.

Alignment and inference of trees. The ssu-rDNA sequence from QPX was aligned in stages against the eukaryotic ssu-rDNA database. Using the alignment editor AE2 (Maidak et al. 1997), the QPX sequence was first juxtaposed manually with the most similar sequences already in the alignment database so as to maximize sequence similarity. Then, positions with significiant covariations and within potential secondary-structural helices were adjusted to maintain basepairing in the secondary-structure model (reviewed by Gutell et al. 1994).

As preliminary analyses indicated that the ssu-rDNA of QPX grouped with thraustochytrids and labyrinthulids, a subset of 23 ssu-rDNAs, including all available ssu-rDNAs from Labyrinthulomycota and 4 outgroup sequences, was selected for more careful analyses. Removal of structural annotations and empty columns yielded a $23 \times 2046$ matrix, from which 151 columns of phylogenetically uninformative data (e.g., nucleotides present in only 1 species, or idiosyncratic in each of 2 or 3 species) and ambiguously aligned regions (typically associated with size variation of loops) were further deleted to yield the $23 \times 1895$ matrix on which the results presented herein are based. Further, more aggressive removal of sparsely populated columns gave a series of matrices down to $23 \times 1493$ in size, analysis of which produced similar results, although typically with reduced support for specific topological features within the ingroup.

Inference of trees was carried out using programs within version 3.53 of the PHYLIP package (Felsenstein 1989) on a Sun Enterprise 4001 server under UNIX. Maximum-likelihood inference was performed using DNAML with global optimization and assuming a transition-to-transversion ratio of 2.00. Parsimony trees were inferred using DNAPARS, with global optimization and 1000 separately nucleated searches for the shortest tree. Parsimony analysis was bootstrapped using SEQBOOT, DNAPARS and CONSENSE. The neighbor-joining tree was generated using DNADIST (assuming Felsenstein's ML model) and NEIGHBOR.
The order of sequence addition was randomized (jumbled) in all analyses. With the $23 \times 1895$ matrix, all of these approaches produced trees identical in all relevant topological features.

\section{RESULTS}

\section{Culture, enrichment and histology}

The enrichment method using MEM culture included a slight modification of the Bower (1987c) extraction method. Two centrifugation washes were used instead of 3, owing to time constraints imposed by large numbers of samples ( $n=29$ or 30 ) from each location. The MEM incubation temperature used was $20^{\circ} \mathrm{C}$ versus $25^{\circ} \mathrm{C}$ (Kleinschuster et al. 1998), to better reflect the mean ambient growing temperature for the more northerly population of Mercenaria mercenaria.

Kleinschuster et al. (1998) reported that QPX has been kept in culture for up to 6 mo. In this study we were able to maintain QPX in culture for $5 \mathrm{mo}$, but the quality and purity of the viscous QPX 'mats' adhering to the flask walls was noticeably reduced after 2 or 3 mo. Some flasks became contaminated with a fungus-like organism (see below) that was readily distinguished from QPX by its variable diameter and nonseptate rhizoidal growth. This contamination became evident at about 2 mo into culture. Subsequent to the completion of the experiments reported herein, this contamination has been overcome by increasing the frequency of sub-culturing from once per $14 \mathrm{~d}$ to once per $7 \mathrm{~d}$ throughout the culture period.

Interestingly, MEM culture (with subsequent confirmation by microscopy) appears to be significantly more sensitive for detecting QPX than the standard histological methods. The sample of 29 quahaugs from Sam Orr Pond produced positive results in 28 of 29 MEM cultures $(96.7 \%)$ but in only 2 of 29 histology sections (6.7\%; G.S.M. unpubl. data).

\section{DNA sequencing, controls and contaminants}

In all, 3 different ssu-rDNAs were obtained from different samples and enrichments of QPX. From frozen uninfected host tissue we recovered an ssu-rDNA sequence essentially identical to that previously reported (Frischer et al. 1998) for Mercenaria mercenaria. PCR from 3 independent preparations of QPX (frozen biomass from September and fresh biomass from September and December) yielded a single band on agarose gels which upon direct sequencing was devoid of detectable background signal (e.g., from $M$. merceniaria ssu-rDNA) and yielded a sequence that showed 
strong BLAST (basic local alignment search tool; National Center for Biotechnolgy Information, Bethesda, MD) similarity to labyrinthulid ssu-rDNAs. Identical sequence was obtained from all 3 of the QPX preparations. Based on its strong prevalence in QPX preparations and its absence from uninfected controls, this ssu-rDNA was identified as arising from QPX. Finally, 2 preparations from experimentally infected $M$. mercenaria visually identified as being contaminated with a fungus-like organism yielded (after molecular cloning and insert screening), in addition to $M$. mercenaria ssu-rDNA, an ssu-rDNA showing strong BLAST matches to fungal ssu-rDNAs. These preparations were clearly distinguished by their lack of the viscosity associated with enrichments containing QPX. Whether this fungus cooccurred significantly with QPX in the host $M$. mercenaria tissue, or contaminated the preparations at a later stage, was not determined. The QPX and fungal ssu-rDNAs have been deposited in GenBank under accession numbers AF261664 and AF261665 respectively.

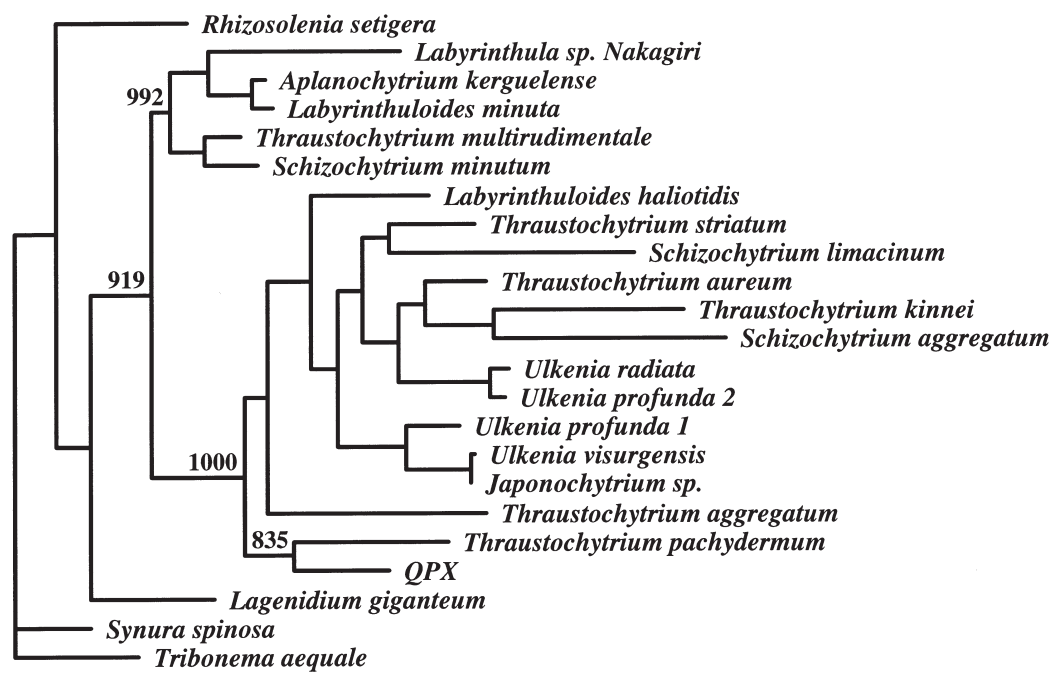

Fig. 1. ssu-rDNA tree showing QPX to be member of Labyrinthulomycota. The non-labyrinthulomycotan ssu-rDNAs are Lagenidium giganteum (oomycete), Rhizosolenia setigera (diatom), Synura spinosa (chrysophyte) and Tribonema aequale (xanthophyte); the latter was set as outgroup. The tree shows the globally optimized maximally likely relationship among these ssu-rDNAs, based on 1895 stably aligned positions at a transition/transversion ratio of 2.00 (see 'Methods and materials'). One rate class of sites was assumed. Bootstrap replicate values (shown above and to the left of selected nodes) were generated by parsimony analysis with $\mathrm{n}=1000$ replicates. The sequence of QPX ssu-rDNA has been deposited in GenBank under accession number AF261664; GenBank accession numbers of other sequences are available on request

\section{Alignment and phylogenetic analysis}

The QPX ssu-rDNA sequence could be aligned with other eukaryotic ssu-rDNAs on the basis of shared sequence and structural similarity. Similarities with ssu-rDNAs from thraustochytrids and labyrinthulids were apparent at this stage. The alignment database and secondary-structure models are highly refined, having undergone more than 15 yr of analysis, evaluation and refinement (Gutell 1999), and few if any ambiguities were apparent upon addition of the ssu-rDNA of QPX.

Topologically similar phylogenetic trees were generated from the 1895-position aligned matrix using different inference methods (likelihood, parsimony, neighbor-joining). The maximum-likelihood tree (Fig. 1), selected on the basis of more general methodological considerations, reveals labyrinthulomycete ssu-rDNAs to fall into 2 subgroups that do not correlate well with existing concepts of genus. The ssu-rDNA of QPX is a member of the betterrepresented of these 2 subgroups, within which it and the ssu-rDNA of Thraustochytrium pachydermum together constitute a basal branch. A strong bootstrap value (919/1000) for the Labyrinthulomycota clade itself, extremely strong bootstrap values for each of the 2 major subgroups therein (1000/1000 for the clade that includes QPX), and a respectable bootstrap value (835/1000) for the grouping of QPX and T. pachydermum, solidify the assignment of QPX to phylum Labyrinthulomycota.

\section{DISCUSSION}

The ssu-rDNA evidence supports ultrastructural evidence that QPX is related to thraustochytrids and/or labyrinthulids. Members of phylum Labyrinthulomycota are characterized by the presence of sagenogens (Olive 1975, p. 223), also called sagenogenetosomes (Perkins 1972) or bothrosomes, that are located immediately under the cell surface and appear to be responsible for producing the ectoplasmic network that attaches these organisms to the substratum and is involved in nutrient uptake (Porter 1990, p. 388). Although sagenogens (sagenogenetosomes) have not been reported in QPX from some localities (see 'Introduction'), the presence of a 'sagenogenetosome-like structure' in QPX from Atlantic Canada (Whyte et al. 1994) would, if homologous with the sagenogens of labyrinthulids, suggest strongly that QPX is a member of Labyrinthulomycota. 
The intermingling of labyrinthuloid and thraustochytrid species in the ssu-rDNA tree (Fig. 1) is not necessarily unexpected. Several ultrastructural features group Labyrinthula species and thraustochytrids (Perkins 1972); for example, the slimeways of Labyrinthula and the rhizoid-like structures of thraustochytrids are both ectoplasmic extensions, production of which involves the sagenogen in an as-yet-poorly understood manner. Many observers have remarked on the variability of morphological characters in these organisms, and Olive (1975, p. 218) noted that '(t)here is already too much confusion in the identification of isolates both at the generic and specific levels'. Further studies, both morphological and molecular, are clearly required before a stable genus-level classification can be proposed.

The labyrinthulomycete most closely related by ssurDNA sequence to QPX, Thraustochytrium pachydermum, has been collected from saline soil environments in Europe and USA (Scholz 1958, Johnson \& Sparrow 1961, Ulken 1977, 1983). This organism produces spherical sporangia (Scholz 1958, Fig. 4; Johnson \& Sparrow 1961, Fig. 119) remarkably reminiscent of sporangia of QPX (Kleinschuster et al. 1998, Fig. 2), but beyond this, specific affinities between the two are not obvious. Gaertner (1972) placed T. pachydermum with 4 other species (T. roseum, T. striatum, T. globosum, T. aggragatum) in the subset of Thraustochytrium in which new sporangia do not proliferate within empty walls of old sporangia, and the sporangial walls are either persistent or deliquescent. Although not all of these species are represented in the ssu-rDNA tree (Fig. 1), the presence in the same major subgroup of Labyrinthulomycota of $T$. aureum and $T$. kinnei (in which new sporangia do proliferate within empty walls of old sporangia) and Ulkenia visurgensis (where the sporangial wall deliquesces before cleavage and emergence of the biflagellate zoospores) makes it clear that the characters on which Gaertner based his classification are not synapomorphies.

Labyrinthulomycetes are ubiquitous in estuarine and marine environments, occurring as epiphytes on marine plants and seaweeds, and associated with decaying plant material and organic detritus. Standard tissue collection for histology entails removal of the mantle edge and siphon prior to removal of the dorsoventral section in order to reduce sand and grit contamination of the subsequent tissue block preparations. This may remove some foci of infection, although gill and other commonly infected tissue sites (Smolowitz et al. 1998) are retained. Thus it is possible that QPX is a ubiquitous marine organism and is present sub-clinically on the surfaces of the mantle and gills, but is detected only infrequently owing to loss during processing for histology. If so, measures for controlling
QPX may more appropriately be focussed on reduction of stocking densities of Mercenaria mercenaria, and on careful attention to disease status of hatchery stocks (Bower et al. 1994, p. 95). Alternatively, there could be 2 or more morphologically similar populations of organisms, only some of which are potentially pathogenic. It would then be of interest to distinguish these populations in natural and hatchery conditions, and determine what triggers pathogenesis. These issues are currently under investigation using DNA hybridization probes based on the ssu-rDNA sequence described in this report.

Acknowledgements. We gratefully acknowledge support of Fisheries and Oceans Canada (S.E.M.), the US National Institutes of Health grant GM48207 (R.R.G.), and the National Research Council of Canada (M.A.R.). M.A.R. additionally thanks the Canadian Institute for Advanced Research, Program in Evolutionary Biology for support. Issued as NRCC 42324 .

\section{LITERATURE CITED}

Bower SM (1987a) Labyrinthuloides haliotidis n. sp. (Protozoa: Labyrinthulomorpha), a pathogenic parasite of small juvenile abalone in a British Columbia mariculture facility. Can J Zool 65:1996-2007

Bower SM (1987b) Pathogenicity and host specificity of Labyrinthuloides haliotidis (Protozoa: Labyrinthulomorpha), a parasite of juvenile abalone. Can J Zool 65:2008-2012

Bower SM $(1987 \mathrm{c})$ Artificial culture of Labyrinthuloides haliotidis (Protozoa: Labyrinthulomorpha), a pathogenic parasite of abalone. Can J Zool 65:2013-2020

Bower SM, McGladdery SE, Price IM (1994) Synopsis of infectious diseases and parasites of commercially exploited shellfish. Annu Rev Fish Dis 4:1-199

Drinnan RE, Henderson EB (1963) 1962 mortalities and a possible disease organism in Neguac quahaugs. Annu Rep No. B11, Biological Station, St. Andrews, New Brunswick

Felsenstein J (1989) PHYLIP-phylogeny inference package. Cladistics 5:164-166

Frischer ME, Danforth JM, Tyner L, Leverone J, Marelli D, Arnold W, Blake NJ (1998) Mercenaria mercenaria 18S ribosomal RNA gene, partial sequence. GenBank accession AF106073. National Center for Biotechnolgy Information, Bethesda, MD (accessed: March 1999); available at http://www.ncbi.nlm.nih.gov/

Gaertner AM (1972) Characters used in the classification of thraustochytriaceous fungi. Ver Inst Meeresforsch Bremerh 13:183-194

Gutell RR (1999) Comparative analysis of RNA sequences. Symposium on RNA biology. Nucleic Acids Res Symp Ser 41:48-53

Gutell RR, Larsen N, Woese CR (1994) Lessons from an evolving ribosomal RNA: $16 \mathrm{~S}$ and 23S rRNA structure from a comparative perspective. Microbiol Rev 58:10-26

Howard DW, Smith CS (1983) Histological techniques for marine bivalve mollusks. National Oceanic and Atmospheric Adminstration Technical Memorandum NMFS-F/ NEC-25, Woods Hole, MA

Johnson TW Jr, Sparrow FK Jr (1961) Fungi in oceans and estuaries. Cramer, Weinheim

Kleinschuster SJ, Smolowitz R, Parent J (1998) In vitro life 
cycle and propagation of quahog parasite unknown. J Shellfish Res 17:75-78

Maidak BL, Olsen GJ, Larsen N, Overbeek R, McCaughey MJ, Woese CR (1997) The RDP (Ribosomal Database Project). Nucleic Acids Res 25:109-111

McGladdery SE, Drinnan RE, Stephenson MF (1993) A manual of parasites, pests and diseases of Canadian Atlantic bivalves. Can Tech Rep Fish Aquat Sci 1931

Olive LS (1975) The mycetozoans. Academic Press, New York

Perkins FO (1972) The ultrastructure of holdfasts, 'rhizoids', and 'slime tracks' in thraustochytriaceous fungi and Labyrinthula spp. Arch Microbiol 84:95-118

Pokorny KS (1967) Labyrinthula. J Protozool 14:697-708

Porter D (1990) Phylum Labyrinthulomycota. In: Margulis L, Corliss JO, Melkonian M, Chapman DJ (eds) Handbook of Protoctista. Jones and Bartlett, Boston, p 388-398

Sambrook J, Fritsch EF, Maniatis T (1989) Molecular cloning. A laboratory manual, 2nd edn. Cold Spring Harbor Laboratory Press, Cold Spring Harbor, NY

Saunders GW, Kraft GT (1994) Small-subunit rRNA gene se-

Editorial responsibility: Albert Sparks,

Seattle, Washington, USA quences from representatives of selected families of the Gigartinales and Rhodymeniales (Rhodophyta). 1. Evidence for the Plocamiales ord. nov. Can J Bot 72:1250-1263

Scholz E (1958) Über morphologische Modifikationen bei niederen Erdphycomyceten und Beschreibung zweier neuer Arten von Rhizophydium und Thraustochytrium. Arch Mikrobiol 29:354-362

Smolowitz R, Leavitt D, Perkins F (1998) Observations of the protistan disease similar to QPX in Mercenaria mercenaria (hard clams) from the coast of Massachusetts. J Invertebr Pathol 71:9-25

Ulken A (1977) Phycomyceten aus der Laguna de Manginga, Veracruz, Mexico. Ver Inst Meeresforsch Bremerh 16: $177-189$

Ulken A (1983) Phycomyceten im Watt des Jadebusens. Ver Inst Meeresforsch Bremerh 19:177-183

Whyte SK, Cawthorn RJ, McGladdery SE (1994) QPX (Quahaug Parasite X), a pathogen of northern quahaug Mercenaria mercenaria from the Gulf of St. Lawrence, Canada. Dis Aquat Org 19:129-136

Submitted: November 2, 1999; Accepted: June 18, 2000 Proofs received from author(s): September 13, 2000 